\title{
Curcumin and resveratrol suppress dextran sulfate sodium-induced colitis in mice
}

\author{
LIZE ZHANG $^{1}$, HUI XUE ${ }^{2}$, GANG ZHAO $^{1}$, CUIXIA QIAO ${ }^{1}$, XIAOMEI SUN ${ }^{1}$, \\ CHENGJIAN PANG ${ }^{1}$ and DIANLIANG ZHANG ${ }^{3}$
}

\author{
${ }^{1}$ Department of Anorectal, The Affiliated Hospital of Qingdao University; \\ ${ }^{2}$ Department of Gynecology, Qingdao Hospital of Traditional Chinese Medicine, Qingdao, Shandong 266000; \\ ${ }^{3}$ Center of Colon and Rectum, Qingdao Municipal Hospital, Qingdao, Shandong 266011, P.R. China
}

Received January 31, 2018; Accepted February 6, 2019

DOI: $10.3892 / \mathrm{mmr} .2019 .9974$

\begin{abstract}
Curcumin and resveratrol are two natural products, which have been described as potential anti-inflammatory, anti-tumor, and anti-oxidant molecules. The aims of the present study were to investigate the protective effect of curcumin and resveratrol on dextran sulfate sodium (DSS)-induced ulcerative colitis (UC) in mice, in addition to understanding the underlying molecular mechanisms. In order to accomplish this, $\mathrm{BALB} / \mathrm{c}$ mice received drinking water containing 3.5\% DSS. Curcumin $(50 \mathrm{mg} / \mathrm{kg} /$ day) or resveratrol $(80 \mathrm{mg} / \mathrm{kg} /$ day $)$ were administered orally for 7 days. Survival rate, body weight, disease activity index score, colon length, pro-inflammatory cytokines, and the expression autophagy-associated proteins, and mechanistic target of rapamycin (mTOR) and sirtuin 1 (SIRT1) were measured. Curcumin or resveratrol treatment prolonged the survival of mice with UC, reduced body weight loss and attenuated the severity of the disease compared with the DSS-treated mice. This effect was associated with a substantial clinical amelioration of the disruption of the colonic architecture and a significant reduction in pro-inflammatory cytokine production. Furthermore, curcumin or resveratrol significantly downregulated the expression of autophagy-related 12, Beclin-1 and microtubule-associated protein light chain $3 \mathrm{II}$, and upregulated the expression of phosphorylated mTOR and SIRT1 in the colon tissue, compared with those in the DSS-treated group. These results suggest that curcumin and resveratrol exert protective effects on DSS-induced UC, partially through suppressing the intestinal inflammatory cascade reaction, reducing autophagy and regulating SIRT1/mTOR signaling.
\end{abstract}

Correspondence to: Dr Dianliang Zhang, Center of Colon and Rectum, Qingdao Municipal Hospital, 1 Jiaozhou Road, Qingdao, Shandong 266011, P.R. China

E-mail:phdzdl@yahoo.com

Key words: curcumin, resveratrol, ulcerative colitis, pro-inflammatory cytokines, autophagy, sirtuin $1 /$ mechanistic target of rapamycin signaling pathway

\section{Introduction}

Ulcerative colitis (UC) is a major type of inflammatory bowel disease (IBD), which are a group of diseases characterized by a chronic and relapsing inflammatory disorder of the large intestine with subsequent injury and disruption of the mucosal barrier (1). Bloody mucopurulent stool, diarrhea, abdominal pain, and fistulization are the most common symptoms of UC $(2,3)$. Although numerous studies suggest that genetic, immunological and environmental factors are involved in the development of UC (3-5), its cause and potential underlying mechanisms are still not clearly understood. In addition, the types of drugs available for the treatment of $\mathrm{UC}$ at present are not abundant and their effects are unsatisfactory; thus, there remains a need to develop novel, effective drugs (6,7). Previous studies have revealed that the dysregulation of inflammatory pathways and autophagy may be involved in the pathogenesis of UC, and thus may be novel therapeutic targets for UC treatment $(8,9)$.

Curcumin is the main component of turmeric (Curcuma longa) (10). Curcumin has attracted considerable attention due to its anti-inflammatory, anti-tumor and anti-oxidant properties (11-13). The anti-inflammatory properties of curcumin have resulted in its use in the treatment of colitis, and previous studies have demonstrated that it is able to attenuate inflammation associated with experimental colitis $(14,15)$ and is effective in patients with UC $(16,17)$. Resveratrol, a natural polyphenolic compound present in grapes and red wine, has been reported to exhibit a variety of anti-oxidant, anti-platelet aggregation, anti-tumor and anti-inflammatory effects, in addition to cardioprotective effects $(18,19)$. Due to the anti-inflammatory characteristics of resveratrol, its use may be therapeutically beneficial in the treatment of a number of different diseases, including colitis (20), arthritis (21) and pancreatitis (22). However, the exact molecular mechanisms involved remain unclear.

Autophagy is an intracellular pathway responsible for turnover of long-lived proteins and damaged organelles to maintain cellular homeostasis (23). Autophagy dysregulation is associated with an alteration of both innate and adaptive immune responses, which has been shown to be involved in many diseases including IBD $(24,25)$. The present study 
evaluated the effect of curcumin and resveratrol on dextran sulfate sodium (DSS)-induced colitis in BALB/c mice and preliminarily investigated the autophagy-associated mechanisms.

\section{Materials and methods}

Animals. Male BALB/c mice (7-8 weeks old), weighing 20-22 g were purchased from Shanghai SLAC Laboratory Animal Co., Ltd. (Shanghai, China) and fed in a controlled environment at a temperature of $25 \pm 2^{\circ} \mathrm{C}$ and a $12 \mathrm{~h} \mathrm{light/dark}$ cycle at $50-70 \%$ humidity. Animals were acclimatized for 1 week prior to the initiation of the study and were maintained with ad libitum access to standard laboratory chow and water. All animal procedures were ethically approved by the Institutional Animal Care and Use Committee of Qingdao Municipal Hospital (Qingdao, China).

Experimental design. A total of 80 mice were randomly divided into four groups: Control group, DSS group, curcumin-treated (DSS + Cur) group, and resveratrol-treated (DSS + Res) group, with 20 mice per group. In the control group, mice were fed with a standard diet throughout the course of the experiment (14 days). In the DSS group, the mice received a standard diet for 14 days in addition to DSS (3.5\% w/v) during the first 7 days of the experiment (from day 1 to 7). In the DSS + Cur group, the mice received the standard diet supplemented with $50 \mathrm{mg} / \mathrm{kg}$ curcumin for 14 days in addition to 3.5\% DSS during the first 7 days of the study. In the DSS + Res group, the mice received the standard diet supplemented with $80 \mathrm{mg} / \mathrm{kg}$ resveratrol for 14 days in addition to $3.5 \%$ DSS during the first 7 days.

Assessment of colitis. The mice were assessed daily for colitis development by monitoring body weight, gross rectal bleeding, stool consistency and survival. Mice were sacrificed by cervical dislocation at day 15 or judged as moribund (inability or unwillingness to walk, inability to reach water or food, palpable hypothermia, or lack of overt response to manipulation) before day 15 and immediately sacrificed, and the colons were removed, length and weight were measured. Scoring systems are used to assess the severity of overall disease (26), and the disease activity index (DAI) was calculated daily for each mouse. In brief, the scoring was as follows: 0 , no weight loss, no occult blood in the stools and normal stool consistency; 1 , weight loss of $1-5 \%$ of total body mass, no occult blood and normal stool consistency; 2, 5-10\% weight loss of total body mass, positive for fecal occult blood and loose stools; $3,10-20 \%$ weight loss of total body mass, positive for fecal occult blood and loose stools; and 4, >20\% weight loss of total body mass, gross rectal bleeding and diarrhea.

Histopathological examinations. Mice were sacrificed on day 8 or 15 by cervical dislocation, and the length of the colon was measured. Samples for histology were excised from the distal $6-8 \mathrm{~cm}$ of the colon, fixed in $10 \%$ formalin overnight at room temperature and embedded in paraffin blocks. Paraffin blocks were sliced into sections, $4 \mu \mathrm{m}$ in thickness, and stained with hematoxylin for $6 \mathrm{~min}$ and eosin (cat. no. C0105; Beyotime Biotechnology, Shanghai, China) for $1 \mathrm{~min}$ at room temperature.
Measurement of cytokines. The concentrations of tumor necrosis factor- $\alpha$ (TNF- $\alpha$ ) and interleukin-6 (IL-6) in the culture supernatants of the colon tissues were measured using a Bio-Rad Multiplex bead array instrument and cytokine kits (cat. no. \#7050; Bio-Rad Laboratories, Inc., Hercules, CA, USA) according to the manufacturer's protocol.

Immunofluorescence staining. Double immunofluorescence staining for autophagy-related 12 (Atg12), Beclin-1, microtubule-associated protein light chain 3 (LC3)II, phospho-mechanistic target of rapamycin (mTOR) and sirtuin 1 (SIRT1) were performed on the sections. Paraffin sections were deparaffinized with xylene and rehydrated. After endogenous peroxidase activity was blocked with $3 \% \mathrm{H}_{2} \mathrm{O}_{2}$ for $10 \mathrm{~min}$ at room temperature, the sections were treated with $0.01 \mathrm{~mol} / 1$ citrate $(\mathrm{pH} 6.0)$ in a $500-\mathrm{W}$ microwave oven for $15 \mathrm{~min}$ for antigen retrieval. Subsequently, sections were blocked with normal goat serum (cat. no. 16210-064; Gibco; Thermo Fisher Scientific, Inc., Waltham, MA, USA) for $1 \mathrm{~h}$, and incubated with the following primary antibodies overnight at $4^{\circ} \mathrm{C}$ : Atg12 (cat. no. ab155589), Beclin-1 (cat. no. ab62557), LC3B (cat. no. ab48394), mTOR (phospho S2448; cat. no. ab84400) and SIRT1 (cat. no. ab32441; all 1:1,000 dilution; all from Abcam, Cambridge, MA, USA). Then, Alexa Fluor 594 (red)-conjugated goat anti-rabbit immunoglobulin G secondary antibody (1:1,000; cat. no. A-11032; Molecular Probes, Eugene, OR, USA) was incubated with the sections for $1 \mathrm{~h}$ at room temperature. Cell nuclei were stained with DAPI $(1 \mu \mathrm{g} / \mathrm{ml}$; cat no. 12131; Roche Diagnostics, Basel, Switzerland) for $5 \mathrm{~min}$ at room temperature. Images were obtained using a fluorescence microscope (Leica SP-8; Leica Microsystems GmbH, Wetzlar, Germany).

Western blot analysis. Colon samples were homogenized on ice in radioimmunoprecipitation assay lysis buffer (Beyotime Institute of Biotechnology, Haimen, China) containing phenylmethylsulfonyl fluoride and protease inhibitor. The protein concentrations of the samples were determined using the Bradford method (using a Bio-Rad Protein assay; Bio-Rad Laboratories, Inc.). Equivalent amounts of protein $(50 \mu \mathrm{g})$ from each sample were separated on $12 \%$ sodium dodecyl sulfate-polyacrylamide gels, and fractioned proteins were transferred onto $0.22 \mu \mathrm{M}$ nitrocellulose membranes (EMD Millipore, Billerica, MA, USA) at $75 \mathrm{~V}$ for $45 \mathrm{~min}$. Subsequently, the membranes were blocked with Tris-buffered saline solution containing 5\% nonfat dried milk at room temperature for $1 \mathrm{~h}$, and then incubated with specific antibodies against Atg12 (cat. no. 2011), Beclin-1 (cat. no. 3495), LC3II (cat. no. 4108), mTOR (cat. no. 2972) and SIRT1 (cat. no. 8469; all 1:1,000 dilution; all from Cell Signaling Technology, Inc., Danvers, MA, USA) at $4^{\circ} \mathrm{C}$ overnight and then incubated with horseradish peroxidase-conjugated secondary antibody (cat. no. 7074; Cell Signaling Technology, Inc.) for $1 \mathrm{~h}$ at room temperature. Bands were visualized using a chemiluminescence detection system (cat. no. \#34095; Pierce; Thermo Fisher Scientific, Inc.) and quantified with Quantity One Software 4.6.7 (Bio-Rad Laboratories, Inc.).

Statistical analysis. Data analysis was performed using GraphPad Prism software (version 4.03; GraphPad Software, 
Inc., La Jolla, CA, USA). Parametric data are presented as the mean \pm standard error of at least three independent experiments. The statistical significance of any difference in each parameter among the groups was evaluated using one-way analysis of variance followed by Tukey's post-hoc test. $\mathrm{P}<0.05$ was considered to indicate a statistically significant difference.

\section{Results}

Effect of curcumin or resveratrol on survival, body weight and the clinical symptoms of mice. Symptomatic parameters, including the survival rate, body weight loss and DAI, caused by colitis in mice were recorded. On day 15 , six mice were randomly selected from each group for body weight and DAI analysis. As presented in Fig. 1A, DSS exposure resulted in a $50 \%$ mortality rate at day 14 , which was similar to the data reported in a previous study (27). However, the survival rate of the DSS-treated mice was improved in the curcumin $(66.7 \%)$ and resveratrol (83.3\%)-treated groups. In the DSS-treated group, a loss of body weight was recorded from day 4 onwards following the administration of DSS (4\%) and this loss remained significantly higher than the normal mice until day $8(83.85 \pm 2.36 \%)(\mathrm{P}<0.05)$. The administration of curcumin or resveratrol significantly reduced the body weight loss in mice with colitis compared with the DSS-treated mice $(\mathrm{P}<0.05$; Fig. 1B). Another common feature of the DSS-induced model of colitis is an increase in the DAI (28). Curcumin or resveratrol treatment significantly ameliorated diarrhea and rectal bleeding compared with the DSS alone-treated group $(\mathrm{P}<0.05$; Fig. 1C).

Effect of curcumin or resveratrol on the colon length and histopathology of mice with colitis. Colon tissues were collected and measured at days 7 and 14, in order to study the effect of curcumin or resveratrol on the inflammation-induced decrease in colon length, a morphological parameter used to assess the degree of inflammation in the DSS-induced colitis mouse model. The colon length of the mice exposed to DSS was significantly shorter compared with that of the control mice $(\mathrm{P}<0.05$; Fig. 2$)$. The colon of mice treated with DSS and curcumin, or DSS and resveratrol exhibit a statistically significant increase in colon length when compared with the DSS group and almost completely reverted to a normal length $(\mathrm{P}<0.05)$.

Histological analysis of the distal colon tissue revealed that the treatment of mice with DSS resulted in the destruction of colonic architecture with ulcerations, crypt dilation, goblet cell depletion, a disrupted epithelial layer and intense infiltration of the inflammatory cells compared with the normal morphology of colon tissue (Fig. 2B). By contrast, colon tissues from the curcumin or resveratrol-treated mice exhibited predominantly intact colon histology, with a preserved epithelial layer and crypt structure, and reduced numbers of infiltrating cells (Fig. 2B).

Effect of curcumin and resveratrol on the production of inflammatory cytokines in the colon tissue of mice with colitis. Colonic TNF- $\alpha$ and IL-6 levels were significantly elevated in the DSS group compared with the controls $(\mathrm{P}<0.05$; Fig. 3$)$. Curcumin or resveratrol administration prevented significant increases in
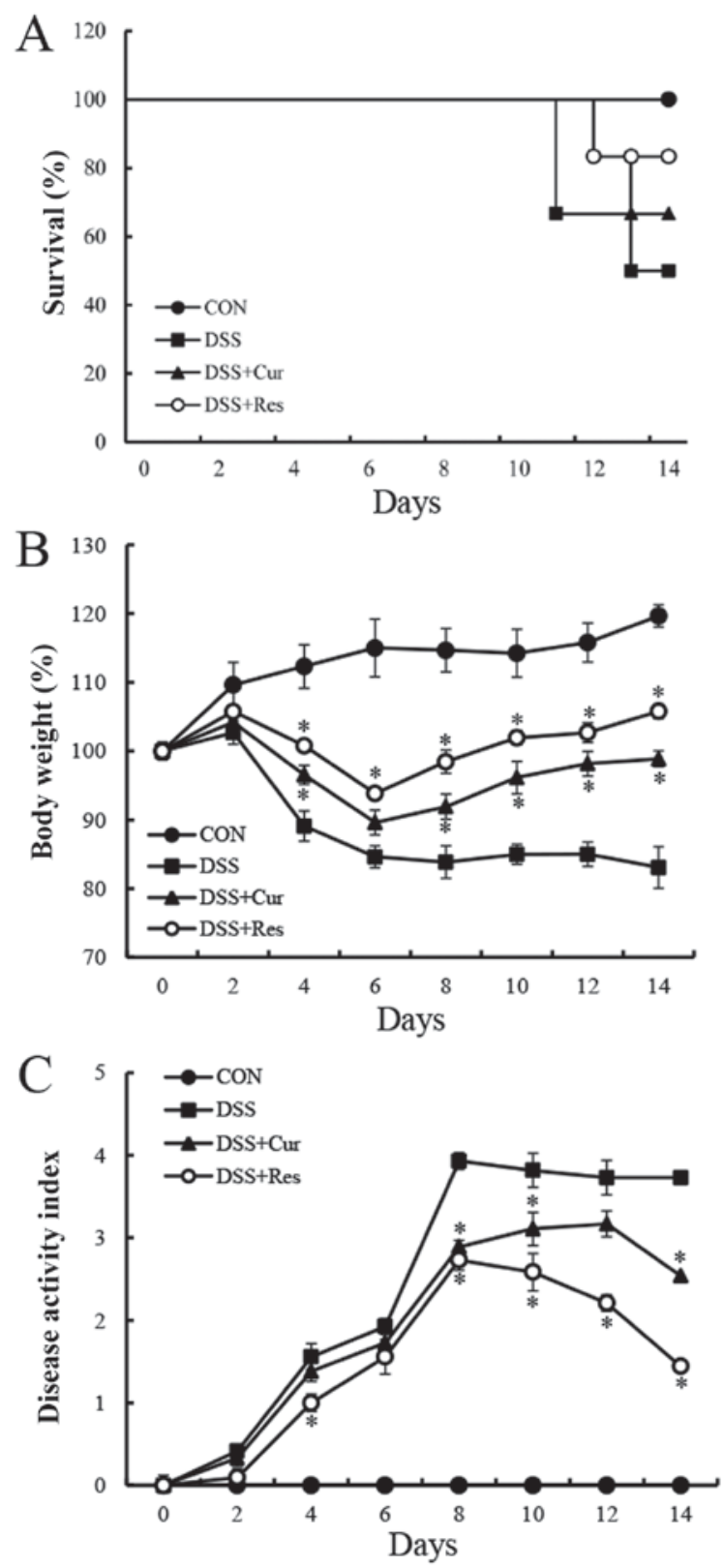

Figure 1. Effect of curcumin or resveratrol treatment on survival rate and clinicopathological symptoms of the mice. (A) Survival rates, (B) the percentage change in body weight and $(\mathrm{C})$ the disease activity index of curcumin or resveratrol-treated mice and control mice (which had been administered 3.5\% DSS) were monitored every day. Data are presented as the mean \pm standard error of the mean of six mice per group. ${ }^{*} \mathrm{P}<0.05$ vs. the DSS alone group. CON, control; DSS, dextran sulfate sodium; Cur, curcumin; Res, resveratrol.

TNF- $\alpha$ and IL-6 expression levels at day $7(\mathrm{P}<0.05)$. Similar effects of curcumin or resveratrol treatment were observed at day 14.

Effect of curcumin and resveratrol on autophagy in $D S S$-induced UC in mice. Immunofluorescence staining for components of cellular autophagy signaling pathways, including Atg12, Beclin-1 and LC3II, was performed on colon tissues. As presented in Fig. 4A, a marked increase in the expression of the autophagy-associated proteins Atg12, Beclin-1 and LC3II was observed in the DSS-treated mice when compared with the control mice $(\mathrm{P}<0.05)$. LC3I expression also appeared to 


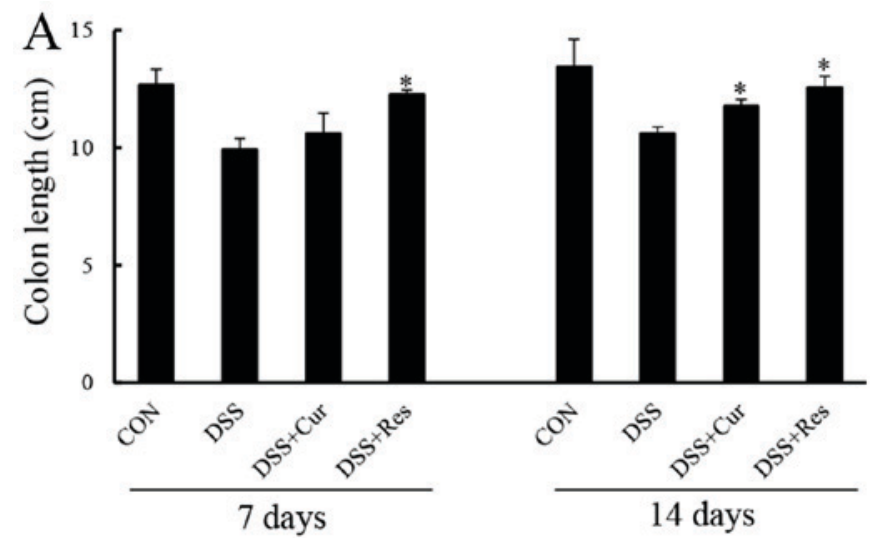

B

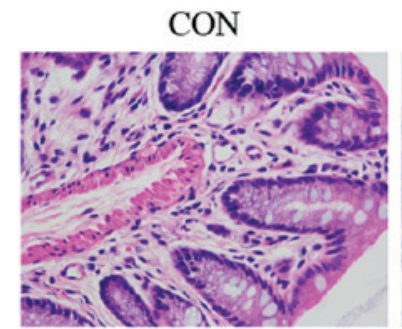

DSS+Cur
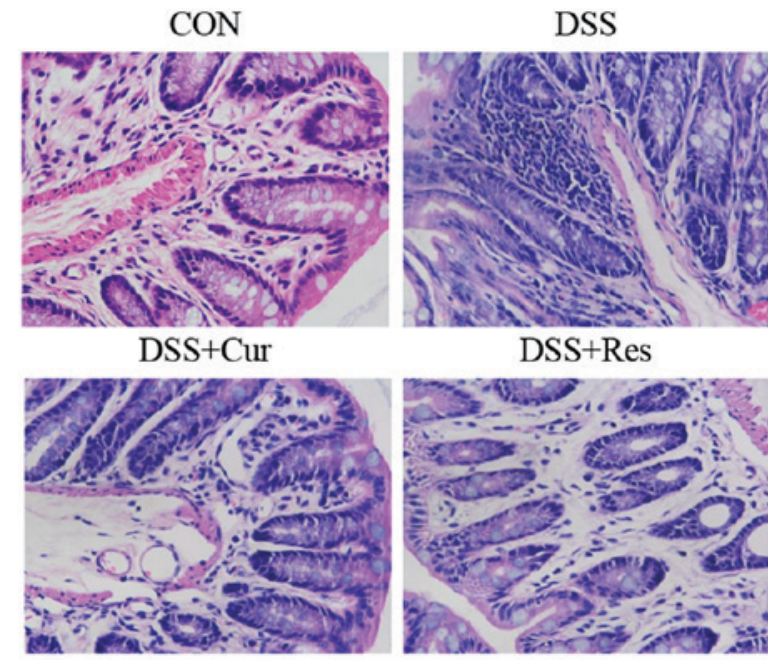

DSS+Res

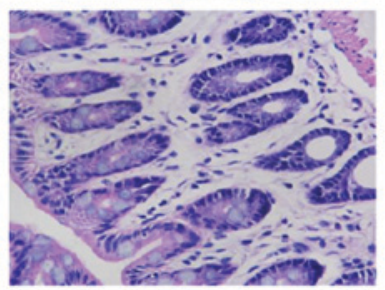

Figure 2. Effect of curcumin or resveratrol treatment on colon length and histopathological changes of the colon tissue of DSS-induced ulcerative colitis. Colons were obtained 7 and 14 days following DSS administration. (A) The colon length was measured and analyzed. (B) Representative images of hematoxylin and eosin staining of colon tissues from each group were obtained using light microscopy at a magnification of $x 400$. Data are presented as the mean \pm standard error of six mice per group. ${ }^{*} \mathrm{P}<0.05$ vs. the DSS alone group. CON, control; DSS, dextran sulfate sodium; Cur, curcumin; Res, resveratrol.

increase. Treatment with curcumin or resveratrol significantly reversed the changes in the levels of autophagy-associated genes when compared with the DSS-treated mice $(\mathrm{P}<0.05)$. To further confirm this observation, the LC3II, Atg12 and Beclin-1 expression, and the LC3II/I ratio were assessed using western blot analysis (Fig. 4B). The expression levels of Atg12, Beclin-1 and LC3II were significantly increased by exposure to DSS $(\mathrm{P}<0.05)$, and curcumin or resveratrol treatment significantly reduced their expression.

Effect of curcumin and resveratrol on mTOR and SIRTI expression in DSS-induced UC in mice. Furthermore, the present study intended to investigate whether the inhibition of autophagy was mediated via mTOR and SIRT1 activation. As determined by immunofluorescence staining and western blot analysis, a substantial decrease in the protein expression levels of phospho-mTOR and SIRT1 were observed in the DSS group compared with the normal mice (Fig. 5A and B). Additionally, phospho-mTOR and SIRT1 demonstrated a higher expression

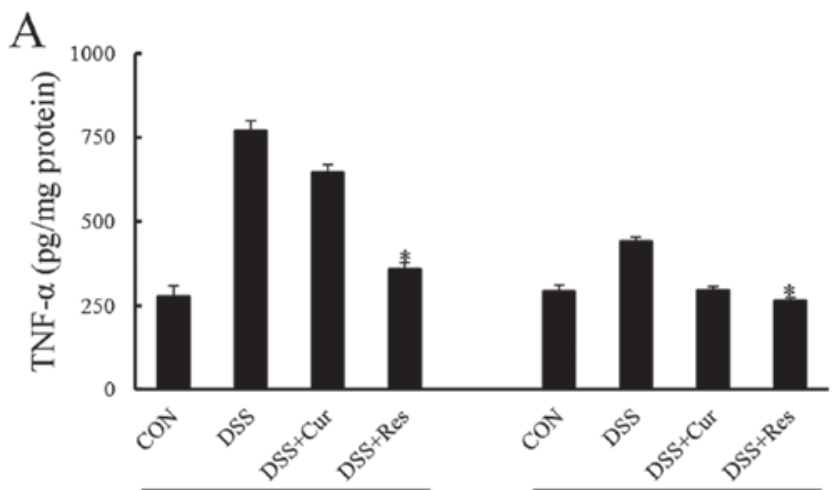

7 days

14 days

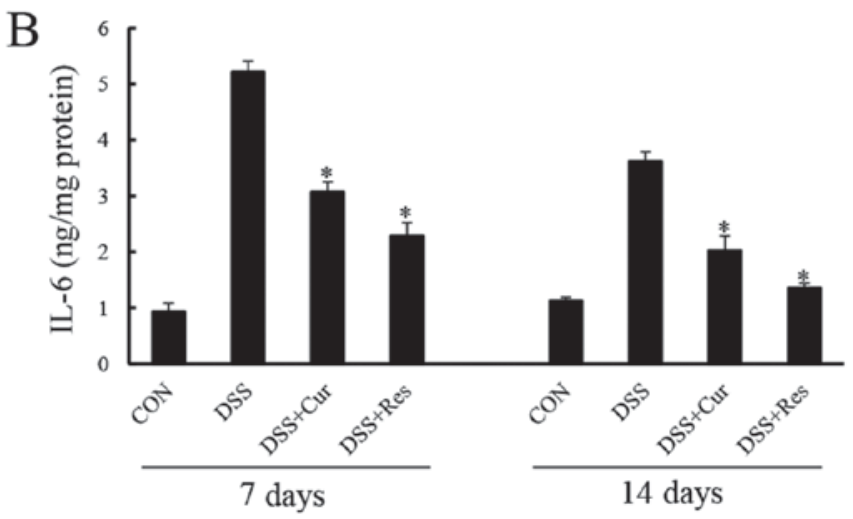

Figure 3. Effect of curcumin or resveratrol treatment on the inflammatory biomarkers of DSS-induced ulcerative colitis. The expression of colonic pro-inflammatory cytokines (A) tumor necrosis factor- $\alpha$ and (B) IL-6 were assessed using a Multiplex Bead array. Data are presented as the mean \pm standard error of six mice per group. ${ }^{*} \mathrm{P}<0.05$ vs. the DSS alone group. TNF- $\alpha$, tumor necrosis factor- $\alpha$; CON, control; DSS, dextran sulfate sodium; Cur, curcumin; Res, resveratrol; IL-6, interleukin-6.

in the curcumin or resveratrol-treated groups compared with the DSS alone treated group.

\section{Discussion}

Administration of DSS to animals is a frequently used as a model of UC, as the resulting pathological features correspond well to those of UC in humans (29). In the present study, a UC model was successfully established by treating mice with 3.5\% DSS for 7 days, and then the protective effects of curcumin and resveratrol were investigated. Following the administration of DSS, the mice exhibited considerable clinical signs of colitis, including weight loss, crypt architectural distortion, colonic epithelial injury, reduced colon length and infiltration of the inflammatory cells. These macroscopic and microscopic alterations were consistent with the findings of previous studies $(30,31)$, and were counteracted by the administration of curcumin and resveratrol. In the survival experiment, $50 \mathrm{mg} / \mathrm{kg}$ curcumin or $80 \mathrm{mg} / \mathrm{kg}$ resveratrol treatment prolonged animal survival compared with the DSS treatment alone. These observations clearly suggested that curcumin and resveratrol suppress the overt clinical features of DSS-induced colitis.

Curcumin and resveratrol treatment in the present study resulted in the preservation of histological integrity in the colon tissue. The DSS-induced mice developed immunological 

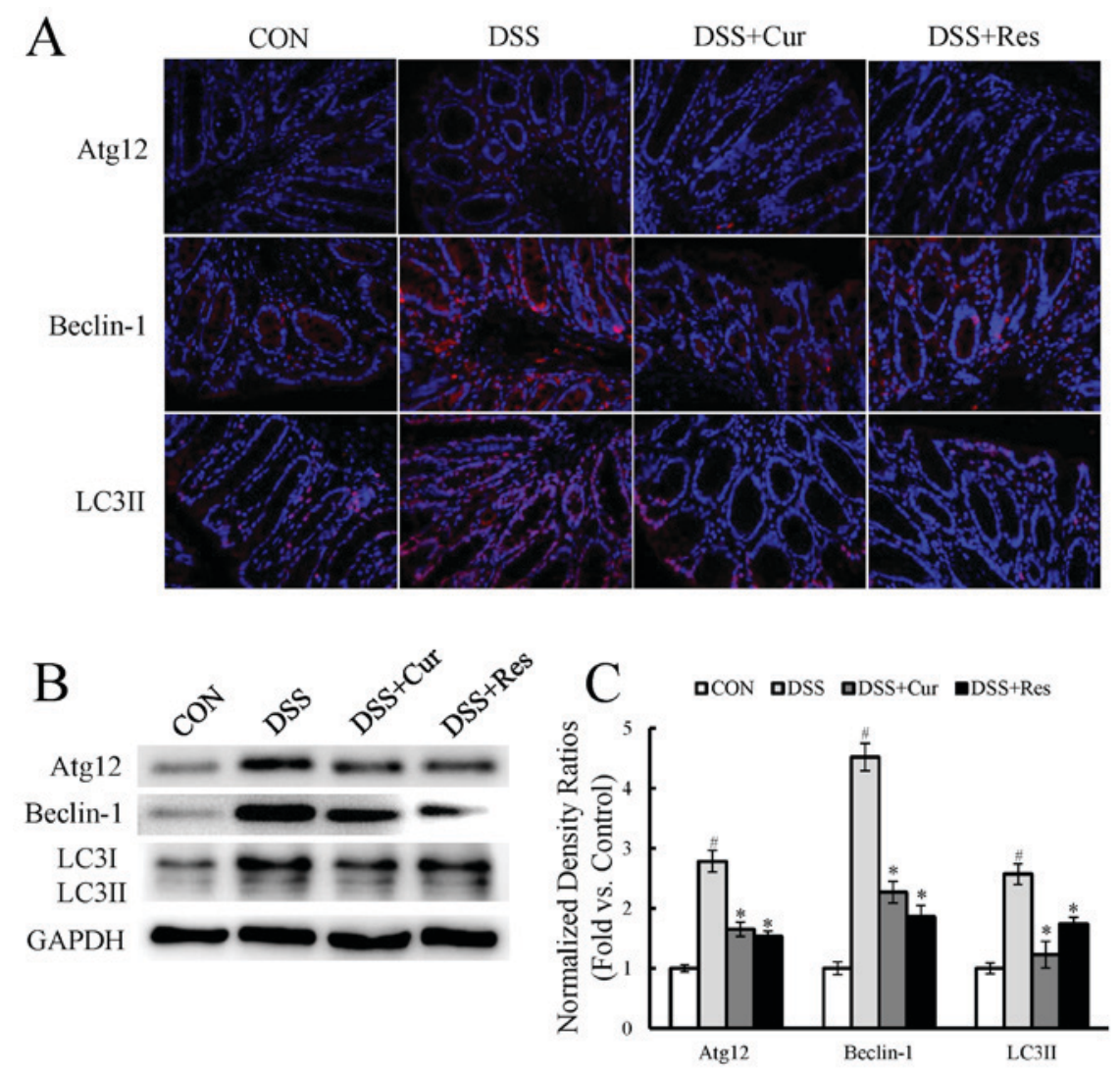

Figure 4. Effect of curcumin or resveratrol treatment on the expression of autophagy-associated genes in colon tissues. (A) Immunofluorescence staining for Atg12, Beclin-1 and LC3B (red) and nucleus (green). (B) Representative western blots presenting the relative protein expression of autophagy-associated proteins in the colon tissue. (C) Densitometry analysis of the western blots. Data are presented as the mean \pm standard error of six mice per group. $\mathrm{P}<0.05 \mathrm{vs}$. the CON group; ${ }^{\prime} \mathrm{P}<0.05$ vs. the DSS alone group. CON, control; DSS, dextran sulfate sodium; Cur, curcumin; Res, resveratrol; Atg12, autophagy-related 12; LC3, microtubule-associated protein light chain 3.
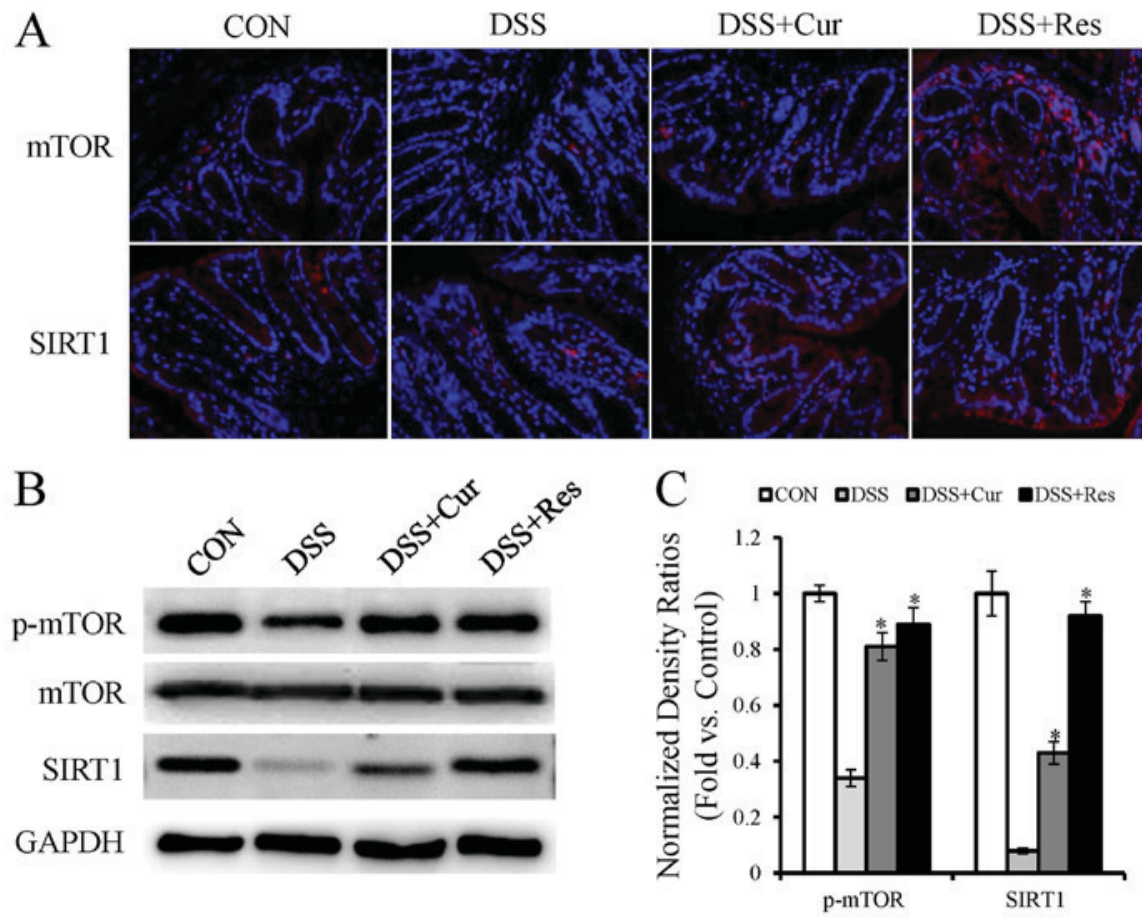

Figure 5. Effect of curcumin or resveratrol treatment on mechanistic target of rapamycin and silent information regulator-1 expression in colon tissue. (A) Immunofluorescence staining for mTOR and SIRT1 (red) and nucleus (green). (B) Representative western blots presenting the relative protein expression of autophagy-associated genes in colon tissue. (C) Graphical depiction of the quantified data of the western blots. Data are presented as the mean \pm the standard error of the mean of six mice per group. ${ }^{*} \mathrm{P}<0.05$ vs. the DSS alone group. CON, control; DSS, dextran sulfate sodium; Cur, curcumin; Res, resveratrol; mTOR, mechanistic target of rapamycin; SIRT1, sirtuin 1; p-, phospho-. 
deregulation (32), including the prominent shortening of the large intestine, thickened muscular layer, crypt damage and cellular infiltration in the inflamed colon; however, these effects were reduced by curcumin and resveratrol treatment.

In addition, curcumin and resveratrol treatment significantly decreased the accumulation of pro-inflammatory cytokines as compared with those in the colon tissue of DSS-treated mice. Inflammatory responses have a pivotal role in the pathogenesis of UC $(33,34)$. A number of previous studies have revealed that the interaction between inflammatory pathways and the intestinal mucosal immune system may result in the disruption of tight junction proteins in the intestinal epithelium and affect intestinal homeostasis $(35,36)$. A number of studies support the idea that TNF- $\alpha$ and IL-6 are important pathological mediators of IBD (37-39). Increased serum and tissue levels of TNF- $\alpha$ and IL- 6 are characteristic features of colitis and numerous other chronic inflammatory diseases (40). Among these cytokines, the overexpression of TNF- $\alpha$ is vital in intestinal mucosal impairment (41). Adalimumab, a TNF- $\alpha$ blocker, has been successfully used for the treatment of patients with IBD in a clinical setting (42). Another anti-TNF- $\alpha$ antibody, infliximab, was also reported to exert an effective therapeutic effect on UC in one clinical case (43). In addition, IL-6 is a key mediator of the progression of UC. Inhibition the action of IL-6 may attenuate the severity of diarrhea and reduce the infiltration of inflammatory cells into the intestinal tissue $(44,45)$. In the present study, TNF- $\alpha$ and IL- 6 production in DSS-exposed colons were substantially higher at 14 days post-DSS compared with curcumin or resveratrol-treated mice, which is consistent with the delayed recovery from inflammation in these mice. These results are supported by previous in vivo and in vitro experiments where curcumin or resveratrol have been demonstrated to suppress the chronic inflammation through the inhibition of these inflammatory mediators (46-48). Altogether, the present results suggest that the protective effect of curcumin and resveratrol against colonic injury may be due to the regulation of TNF- $\alpha$ and IL-6.

Autophagy is a degradative pathway involved in recycling long-lived proteins and damaged organelles in order to maintain cellular homeostasis. It is regulated by autophagy-specific genes that include the Beclin-1 complex, Atg12 and LC3 systems (49). Additionally, the dysregulation of autophagy has been shown to be involved in multiple diseases, such as liver disease, cardiomyopathy, diabetes, neurodegenerative disorders, autoimmune diseases, malignancies and $\operatorname{IBD}(24,50,51)$. Autophagy is regulated by autophagy specific genes, including Beclin-1, which initiates autophagosome formation via the phosphatidylinositol 3-kinase signaling pathway (25). Autophagosome formation is further associated with the conversion of cytosolic-associated protein light chain 3 (LC3-I) to the membrane bound LC3-II form (52). LC3-II is most commonly used for autophagy assays since it is the only protein marker that is reliably associated with the number of autophagosomes (52). However, LC3-II itself is degraded by autophagy (53). The autophagy factor Atg12-Atg5 conjugate has a novel E3-like activity for facilitating the lipidation of members of the LC3 family (54). The results of the present study demonstrated that LC3I, Beclin-1, and the Atg12 protein were highly expressed in the colon of DSS-exposed mice, compared with the control animals. Decreased LC3I, Beclin-1 and Atg12 protein expression was detected in curcumin and resveratrol-treated mice compared with the DSS-treated animals. Upon autophagy induction, LC3-I is cleaved to LC3-II. However, the change of LC3-II in the study is far lower than LC3I, which may be due to the degradation by autophagy (53).

Autophagy is regulated by important nutrient-sensing pathways, including the mTOR and SIRT1 pathways $(55,56)$. mTOR is an evolutionarily conserved serine/threonine kinase which is a member of the phosphoinositide 3-kinase-associated kinase group, and has emerged as a master regulator of cellular metabolism and promotes cell growth in response to environmental cues (57). Deregulation of the mTOR pathway has been implicated in a number of human diseases including diabetes, neurodegenerative diseases, cancer and IBD (57). Tuberous sclerosis complex (TSC) and lymphangioleio-myomatosis are associated with the deregulation of the raptor-mTOR pathway, which are likely caused by mutations in TSC1 or TSC2 tumor suppressors (58). As a consequence, drugs that target mTOR are used therapeutically (59). SIRT1 is a nuclear class III deacetylase and has been demonstrated to extend lifespan in a number of different species (60). Furthermore, SIRT1 has been reported to improve the symptoms of inflammation-associated diseases, including chronic obstructive pulmonary disease, cardiovascular diseases, diabetes, renal diseases and IBD $(60,61)$. In the present study, the expression of phosphorylated mTOR and SIRT1 was greatly increased by curcumin and resveratrol in mice with DSS-induced colitis compared with the DSS alone treated mice, suggesting that the anti-UC effect of curcumin and resveratrol may be due to the promotion of MTOR and SIRT1 signaling activation.

In conclusion, the present study is, to the best of our knowledge, the first to demonstrate that the development and progression of colitis symptoms caused by DSS administration are attenuated by curcumin and resveratrol. The underlying molecular mechanisms involved in inhibiting inflammatory responses, reducing autophagy-associated gene expression and promoting autophagy signaling activation were elucidated. Collectively, as relatively non-toxic natural products combined with substantial anti-inflammatory activity, curcumin and resveratrol have the potential to function as effective anti-IBD therapeutic methods.

\section{Acknowledgements}

Not available.

\section{Funding}

The present study was supported by the Project of Traditional Chinese Medicine Technology Development Program in the Shandong Province (grant no. 2017-201).

\section{Availability of data and materials}

The datasets used or analyzed during the current study are available from the corresponding author on reasonable request. 


\section{Authors' contributions}

Conception and design, LZ, DZ; data acquisition, LZ, HX, GZ; data analysis and interpretation, CQ, XS, CP; manuscript writing, LZ; final approval of manuscript, all authors. All authors are accountable for all aspects of the study.

\section{Ethics approval and consent to participate}

This study has been approved by the Institutional Animal Care and Use Committee of Qingdao Municipal Hospital.

\section{Patient consent for publication}

Not applicable.

\section{Competing interests}

The authors declare that they have no competing interests.

\section{References}

1. Baumgart DC and Sandborn WJ: Inflammatory bowel disease: Clinical aspects and established and evolving therapies. Lancet 369: 1641-1657, 2007.

2. Stenson WF, Tremaine WJ and Cohen RD (eds): Ulcerative Colitis: Clinical manifestations and management. In: Yamada's Atlas of Gastroenterol. John Wiley \& Sons, Ltd., New York, NY, pp216-224, 2016.

3. Baumgart DC and Carding SR: Inflammatory bowel disease: Cause and immunobiology. Lancet 369: 1627-1640, 2007.

4. Hou JK, Abraham B and El-Serag H: Dietary intake and risk of developing inflammatory bowel disease: A systematic review of the literature. Am J Gastroenterol 106: 563-573, 2011.

5. Eaden JA, Abrams KR and Mayberry JF: The risk of colorectal cancer in ulcerative colitis: A meta-analysis. Gut 48: 526-535, 2001.

6. Laharie D, Bourreille A, Branche J, Allez M, Bouhnik Y, Filippi J, Zerbib F, Savoye G, Nachury M, Moreau J, et al: Ciclosporin versus infliximab in patients with severe ulcerative colitis refractory to intravenous steroids: A parallel, open-label randomised controlled trial. Lancet 380: 1909-1915, 2012.

7. Kreijne JE, Lie MR, Vogelaar L and van der Woude CJ: Practical guideline for fatigue management in inflammatory bowel disease. J Crohns Colitis 10: 105-111, 2016.

8. Pedersen J, Coskun M, Soendergaard C, Salem M and Nielsen OH: Inflammatory pathways of importance for management of inflammatory bowel disease. World J Gastroenterol 20: 64-77, 2014.

9. Hooper KM, Barlow PG, Stevens C and Henderson P: Inflammatory bowel disease drugs: A focus on autophagy. J Crohns Colitis 11: 118-127, 2017.

10. Jurenka JS: Anti-inflammatory properties of curcumin, a major constituent of Curcuma longa: A review of preclinical and clinical research. Altern Med Rev 14: 141-153, 2009.

11. Bar-Sela G, Epelbaum R and Schaffer M: Curcumin as an anti-cancer agent: Review of the gap between basic and clinical applications. Curr Med Chem 17: 190-197, 2010.

12. Aggarwal BB, Yuan W, Li S and Gupta SC: Curcumin-free turmeric exhibits anti-inflammatory and anticancer activities: Identification of novel components of turmeric. Mol Nutr Food Res 57: 1529-1542, 2013.

13. Naik SR, Thakare VN and Patil SR: Protective effect of curcumin on experimentally induced inflammation, hepatotoxicity and cardiotoxicity in rats: Evidence of its antioxidant property. Exp Toxicol Pathol 63: 419-431, 2011.

14. Toden S, Theiss AL, Wang X and Goel A: Essential turmeric oils enhance anti-inflammatory efficacy of curcumin in dextran sulfate sodium-induced colitis. Sci Rep 7: 814, 2017.

15. Liu L, Liu YL, Liu GX, Chen X, Yang K, Yang YX, Xie Q, Gan HK, Huang XL and Gan HT: Curcumin ameliorates dextran sulfate sodium-induced experimental colitis by blocking STAT3 signaling pathway. Int Immunopharmacol 17: 314-320, 2013.
16. Lang A, Salomon N, Wu JC, Kopylov U, Lahat A, Har-Noy O, Ching JY, Cheong PK, Avidan B, Gamus D, et al: Curcumin in combination with mesalamine induces remission in patients with mild-to-moderate ulcerative colitis in a randomized controlled trial. Clin Gastroenterol Hepatol 13: 1444-1449. e1, 2015.

17. Baliga MS, Joseph N, Venkataranganna MV, Saxena A, Ponemone V and Fayad R: Curcumin, an active component of turmeric in the prevention and treatment of ulcerative colitis: Preclinical and clinical observations. Food Funct 3: 1109-1117, 2012.

18. Baur JA and Sinclair DA: Therapeutic potential of resveratrol: The in vivo evidence. Nat Drug Discov 5: 493-506, 2006.

19. Tomé-Carneiro J, Larrosa M, González-Sarrías A, Tomás-Barberán FA, García-Conesa MT and Espín JC: Resveratrol and clinical trials: The crossroad from in vitro studies to human evidence. Curr Pharm Des 19: 6064-6093, 2013.

20. Singh UP, Singh NP, Singh B, Singh B, Hofseth LJ, Price RL, Nagarkatti $M$ and Nagarkatti PS: Resveratrol (trans-3,5,4'-trihydroxystilbene) induces SIRT1 and down-regulates nuclear transcription factor-kappaB activation to abrogate dextran sulfate sodium-induced colitis. J Pharmacol Exp Ther 11: 829-839, 2009.

21. Tian J, Chen JW, Gao JS, Li L and Xie X: Resveratrol inhibits TNF- $\alpha$-induced IL-1 $\beta$, MMP-3 production in human rheumatoid arthritis fibroblast-like synoviocytes via modulation of PI3kinase/Akt pathway. Rheumatol Int 33: 1829-1835, 2013.

22. Carrasco C, Holguín-Arévalo MS, Martín-Partido G, Rodríguez $\mathrm{AB}$ and Pariente JA: Chemopreventive effects of resveratrol in a rat model of cerulein-induced acute pancreatitis. Mol Cell Biochem 387: 217-225, 2014.

23. Komatsu M, Kurokawa H, Waguri S, Taguchi K, Kobayashi A, Ichimura Y, Sou YS, Ueno I, Sakamoto A, Tong KI, et al: The selective autophagy substrate p62 activates the stress responsive transcription factor Nrf2 through inactivation of Keap1. Nat Cell Biol 12: 213-223, 2010.

24. Baxt LA and Xavier RJ: Role of autophagy in the maintenance of intestinal homeostasis. Gastroenterology 149: 553-562, 2015.

25. Garcia-Maurino S, Alcaide A and Dominguez C: Pharmacological control of autophagy: Therapeutic perspectives in inflammatory bowel disease and colorectal cancer. Curr Pharm Des 18: 3853-3873, 2012.

26. CooperHS, Murthy S, Shah R and Sedergran D: Clinicopathologic study of dextran sulfate sodium experimental murine colitis. Lab Invest 69: 238-249, 1993.

27. Vochyánová Z, Bartošová L, Bujdáková V, Fictum P, Husník R, Suchý P, Smejkal K and Hošek J: Diplacone and mimulone ameliorate dextran sulfate sodium-induced colitis in rats. Fitoterapia 101: 201-207, 2015.

28. Chassaing B, Aitken JD, Malleshappa M and Vijay-Kuma M: Dextran sulfate sodium (DSS)-induced colitis in mice. Curr Protoc Immunol 104: 15.25. 11-15.25. 14, 2014.

29. Melgar S, Karlsson L, Rehnström E, Karlsson A, Utkovic H, Jansson L and Michaëlsson E: Validation of murine dextran sulfate sodium-induced colitis using four therapeutic agents for human inflammatory bowel disease. Int Immunopharmacol 8: 836-844, 2008.

30. Brown SR and Coviello LC: Extraintestinal manifestations associated with inflammatory bowel disease. Surg Clin North Am 95: 1245-1259, 2015

31. Zhu H and Li YR: Oxidative stress and redox signaling mechanisms of inflammatory bowel disease: Updated experimental and clinical evidence. Exp Biol Med (Maywood) 237: 474-480, 2012.

32. Håkansson $\AA$, Tormo-Badia N, Baridi A, Xu J, Molin G, Hagslätt ML, Karlsson C, Jeppsson B, Cilio CM and Ahrné S: Immunological alteration and changes of gut microbiota after dextran sulfate sodium (DSS) administration in mice. Clin Exp Med 15: 107-120, 2015.

33. Nenci A, Becker C, Wullaert A, Gareus R, van Loo G, Danese S, Huth M, Nikolaev A, Neufert C, Madison B, et al: Epithelial NEMO links innate immunity to chronic intestinal inflammation. Nature 446: 557-561, 2007.

34. Schwanke RC, Marcon R, Meotti FC, Bento AF, Dutra RC, Pizzollatti MG and Calixto JB: Oral administration of the flavonoid myricitrin prevents dextran sulfate sodium-induced experimental colitis in mice through modulation of PI3K/Akt signaling pathway. Mol Nutr Food Res 57: 1938-1949, 2013.

35. Abraham $\mathrm{C}$ and Medzhitov R: Interactions between the host innate immune system and microbes in inflammatory bowel disease. Gastroenterology 140: 1729-1737, 2011. 
36. Neurath MF: Cytokines in inflammatory bowel disease. Nat Rev Immunol 14: 329-342, 2014.

37. Stillie R and Stadnyk AW: Role of TNF receptors, TNFR1 and TNFR2, in dextran sodium sulfate-induced colitis. Inflamm Bowel Dis 15: 1515-1525, 2009.

38. Geremia A, Biancheri P, Allan P, Corazza GR and Di Sabatino A: Innate and adaptive immunity in inflammatory bowel disease. Autoimm Rev 13: 3-10, 2014.

39. Strober W and Fuss IJ: Proinflammatory cytokines in the pathogenesis of inflammatory bowel diseases. Gastroenterology 140 1756-1767. e1751, 2011.

40. Múzes G, Molnár B, Tulassay Z and Sipos F: Changes of the cytokine profile in inflammatory bowel diseases. World J Gastroenterol 18: 5848-5861, 2012.

41. Biasi F, Leonarduzzi G, Oteiza PI and Poli G: Inflammatory bowel disease: Mechanisms, redox considerations, and therapeutic targets. Antioxid Redox Signal 19: 1711-1747, 2013.

42. Fiorino G, Szabo H, Fries W, Malesci A, Peyrin-Biroulet L and Danese S: Adalimumab in Crohn's disease: Tips and tricks after 5 years of clinical experience. Curr Med Chem 18: 1230-1238, 2011.

43. Rutgeerts P, Sandborn WJ, Feagan BG, Reinisch W, Olson A, Johanns J, Travers S, Rachmilewitz D, Hanauer SB, Lichtenstein GR, et al: Infliximab for induction and maintenance therapy for ulcerative colitis. New Eng J Med 353: 2462-2476, 2005.

44. Dionne S, D'Agata D, Hiscott J, Vanounou T and Seidman E: Colonic explant production of IL-1 and its receptor antagonist is imbalanced in inflammatory bowel disease (IBD). Clin Exp Immunol 112: 435-442, 1998.

45. Kwon KH, Murakami A, Hayashi $\mathrm{R}$ and Ohigashi $\mathrm{H}$ : Interleukin-1beta targets interleukin-6 in progressing dextran sulfate sodium-induced experimental colitis. Biochem Biophys Res Commun 337: 647-654, 2005.

46. Zhu HT, Bian C, Yuan JC, Chu WH, Xiang X, Chen F, Wang CS, Feng $\mathrm{H}$ and Lin JK: Curcumin attenuates acute inflammatory injury by inhibiting the TLR4/MyD88/NF- $\kappa \mathrm{B}$ signaling pathway in experimental traumatic brain injury. J Neuroinflammation 11: 59, 2014.

47. Epstein J, Sanderson IR and Macdonald TT: Curcumin as a therapeutic agent: The evidence from in vitro, animal and human studies. Br J Nutr 103: 1545-1557, 2010.

48. Sánchez-Fidalgo S, Cárdeno A, Villegas I, Talero E and de la Lastra CA: Dietary supplementation of resveratrol attenuates chronic colonic inflammation in mice. Eur J Pharmacol 633 78-84, 2010.

49. Klionsky DJ, Cregg JM, Dunn WA Jr, Emr SD, Sakai Y, Sandoval IV, Sibirny A, Subramani S, Thumm M, Veenhuis M and Ohsumi Y: A unified nomenclature for yeast autophagy-related genes. Dev Cell 5: 539-545, 2003.
50. Tschurtschenthaler M, Adolph TE, Ashcroft JW, Niederreiter L, Bharti R, Saveljeva S, Bhattacharyya J, Flak MB, Shih DQ, Fuhler GM, et al: Defective ATG16L1-mediated removal of IRE1 $\alpha$ drives Crohn's disease-like ileitis. J Exp Med 214: 401-422, 2017.

51. Shintani T and Klionsky DJ: Autophagy in health and disease: A double-edged sword. Science 306: 990-995, 2004.

52. Klionsky DJ, Abdelmohsen K, Abe A, Abedin MJ, Abeliovich H, Acevedo Arozena A, Adachi H, Adams CM, Adams PD, Adeli $\mathrm{K}$, et al: Guidelines for the use and interpretation of assays for monitoring autophagy (3rd edition). Autophagy 12: 1-222, 2016.

53. Alayev A, Sun Y, Snyder RB, Berger SM, Yu JJ and Holz MK: Resveratrol prevents rapamycin-induced upregulation of autophagy and selectively induces apoptosis in TSC2-deficient cells. Cell Cycle 13: 371-382, 2014

54. Otomo C, Metlagel Z, Takaesu G and Otomo T: Structure of the human ATG12 ATG5 conjugate required for LC3 lipidation in autophagy. Nat Struct Mol Biol 20: 59-66, 2013.

55. Ou X,Lee MR, Huang X, Messina-Graham S and Brox meyer HE: SIRT1 positively regulates autophagy and mitochondria function in embryonic stem cells under oxidative stress. Stem Cells 32: 1183-1194, 2014.

56. He C and Klionsky DJ: Regulation mechanisms and signaling pathways of autophagy. Annu Rev Genet 43: 67-93, 2009.

57. Laplante M and Sabatini DM: mTOR signaling in growth control and disease. Cell 149: 274-293, 2012.

58. Alves MM, Fuhler GM, Queiroz KC, Scholma J, Goorden S, Anink J, Spek CA, Hoogeveen-Westerveld M, Bruno MJ, Nellist M, et al: PAK2 is an effector of TSC1/2 signaling independent of mTOR and a potential therapeutic target for Tuberous Sclerosis Complex. Sci Rep 5: 14534, 2015.

59. Seinen ML, van Nieuw Amerongen GP, de Boer NK and van Bodegraven AA: Rac attack: Modulation of the small GTPase Rac in inflammatory bowel disease and thiopurine therapy. Mol Diagn Ther 20: 551-557, 2016.

60. Satoh A, Brace CS, Rensing N, Cliften P, Wozniak DF, Herzog ED, Yamada KA and Imai S: Sirtl extends life span and delays aging in mice through the regulation of Nk2 homeobox 1 in the DMH and LH. Cell Metab 18: 416-430, 2013.

61. Singh UP, Singh NP, Singh B, Hofseth LJ, Price RL, Nagarkatti M and Nagarkatti PS: Resveratrol (trans-3,5,4'-trihydroxystilbene) induces silent mating type information regulation-1 and down-regulates nuclear transcription factor-kappaB activation to abrogate dextran sulfate sodium-induced colitis. J Pharmacol Exp Ther 332: 829-839, 2010

(i)(5) This work is licensed under a Creative Commons Attribution-NonCommercial-NoDerivatives 4.0 International (CC BY-NC-ND 4.0) License. 